\title{
The Influence and Countermeasures of FIBA New Rules on Basketball Teaching in Colleges and Universities
}

\author{
Hua Yang \\ Lanzhou University of finance and economics institute of Longqiao, Lanzhou 730101
}

Keywords: new rules of FIBA; basketball teaching in colleges and universities; countermeasures

\begin{abstract}
With the continuous progress of basketball, the traditional basketball model and rules have made a large adjustment. FIBA's new rules have changed a lot in the three-point line distance, lane and attack mode, which changes the basketball tactics and attack mode with new ideas and cognition. Based on the understanding of the current situation of basketball in colleges and universities under the new rules, this paper analyzes the influence of the new rules on basketball and finds out some specific ways to improve basketball teaching in colleges and universities, so as to provide useful references for the better development of basketball teaching in Chinese universities.
\end{abstract}

\section{Introduction}

The evolution of world basketball from traditional competitive sports to today's competitive sports and ornamental organically combined sports forms, basketball sports, regardless of fields, costumes, rules or techniques and tactics, has made progress across the ages. In 2010, the new rules will expand from three FIBA to 0.5 meters, the lane change at the same time limit the expansion of rectangular area, and the addition of offensive favorable areas. The changes in these rules are all in order to make basketball more ornamental. I hope the World Basketball Association Basketball is not a single basket offensive mode, changing tactics and flexible fit to make basketball show new vitality. China's basketball education in Colleges and universities should also uphold the purpose of the new FIBA rules, strengthen the innovative research of technology and tactics under the new rules, and speed up the improvement of basketball level in China [1].

\section{The influence of the new rules of FIBA on Basketball}

The three point in basketball is set by FIBA in 1984, which encourages shot rules began to be established. But the early basketball team pays more attention to the selection of players' quality. Height is a very important index, which makes the teams like to play the inside line at the time, and made many skills and tactics around the center. This single attack mode makes the game seem dull, not with the subtle and stifling shot lore. With the new rules in 2010 FIBA has expanded from three, the three points score becomes not so easy at the same time, give the team more attacking options, how to pull the two sides of the game, how the excellent ability gap outside contain the opponent's defense is a lot of study coach. Under the development of today's basketball mode, the offensive system has not merely played the inside line or the outside line. The team can play more efficient and better basketball tactics through three points of containment, and more and more teams playing small balls stand out. This new development has broken the idea that basketball is only big enough to dominate basketball. Many small excellent pitchers and guards can also be remembered.

In the period of basketball rising, basketball is dominated by many big players. For example, players like Olajuwon and Chamberlain are all above two meters tall. FIBA for the curing of basketball pattern has taken many measures, such as in 1952 the defense restricted area by 3.6 meters expanded to 6 meters, the revised rules can make the defense in advance for high players, tight defense, but also to avoid the blind pursuit of many teams playing basket tactics. This kind of rule restricting the activity range of high players and basketball teams effectively balances the attacking mode of basketball, and enables players to master the comprehensive ability of basketball 
through enhancing their physical quality and learning different basketball skills, and can adapt to all kinds of tactics arranged by coaches. In the latest FIBA rules, the restricted area is changed into rectangle, and the attack range of the tall players is increased. This mode enables the high players to improve their comprehensive quality in order to survive in the new basketball idea [2].

\section{New rules add the favorable area of attack to improve the ornamentability}

Basketball is a sport of high strength, strong anti body test basic quality, in just 48 minutes, the players need to continue running and jumping with every kind of physical and tactical application of basketball players technology implementation of the premise is their own physical conditions. The new FIBA rules to encourage players to exercise seriously, improve the quality of the body, and more fierce confrontation and scraping. In the previous FIBA games, some players will be opportunistic in the basket "diving" for an offensive foul, so only delays the game to lose ornamental, also lost a fair competition environment. There is no offensive foul in the area set up by the new rule of FIBA. There is no offensive foul in this area. Only by blocking the fouls, basketball in this mode appears more stimulating and stimulating. Basketball is a sport that should be hemorrhagic and passionate. The new rule of FIBA is also committed to developing basketball into a more equitable and humane competitive sport.

\section{Countermeasures to improve college basketball teaching under the background of FIBA new rules}

Traditional basketball in Colleges and universities will focus on training those tall players to train their basketball skills. With the continuous reform of FIBA rules, more excellent players are needed in basketball courts. As a basketball player, the innate quality is very important, but the understanding of the sense of the ball, shooting skills, basketball skills and basketball rules is an important part of the comprehensive quality.

First, college basketball training should take basketball knowledge as the starting point, let the players know the rules of basketball and basketball concept, such as noun ancient restricted area, area reasonable collision need to clear the meaning of it to inform other players. Some fuzzy concepts also need to emphasize the foul, such as how to determine a charge or blocking foul, foul and so on is reasonable or cover. The staff in the heart of the rules of basketball has a scale, so that in actual combat, it will maximize its own special skills [3].

Secondly, the college basketball coach should carry out a comprehensive training for the players of different physical qualities. For the tall players, for example, while practicing basketball skills, we should pay attention to the training of their shooting skills. In the training basket, to focus on training the hook shot, backhand shot and close shot, exercise their ability to adapt the unguarded variety of shooting and one case against shooting. The guard type player, to let it adapt to the distance of three lines under the new FIBA rules, as the key role of the pitcher is given at the same time opponents outside threat, defenders need to constantly pass through the body reaches a certain intensity of confrontation training and anti-jamming ability, when talking about the defense team pulled to the outside can choose this breakthrough a way of attack. Players with both internal and external structure can develop into a comprehensive quality player to carry out the coach's tactical intention in actual combat. Since the majority of combat tactics in basketball around the restricted area under the basket arrangement, three principles of attack or defense is the core of contemporary basketball tactics, players need to have the ability to run in the singles, dislocation ball layup or stop shot ability and backs ball turnaround ability. The attack is the basic condition to decide a good basketball player, the player in the university period should do the basic skills of basketball, from the basic movements of each layup and shooting practice, with the amount of training to make up for congenital deficiency, so the training day in and day out if not, tall players but other skills are outstanding, can also shine in the world basketball arena. In today's NBA arena, especially in the small players, especially the non Stephen curri, I like this player very much. He is a representative figure of the new era shooting guard and is also one of the forerunners who changed people's 
traditional basketball concept. Because of the presence of NBA in the library, a new tactical system of a small lineup, the three ball once again pay attention to it, now NBA is not the traditional center around the launch tactics, but how to develop tactics to get the opportunity to open three new era of pattern projection. This situation shows that there is no constant basketball system, only the continuous development of advanced tactics. And as a player, only the continuous training of their own basketball skills can adapt to the continuous development of basketball.

In basketball games, the role of defense is greater than that of attack. Because with the decrease of players' physical strength, the success rate of attack and the hit rate of shooting will be reduced, so defense is the best guarantee for deciding the resilience of a team. The defensive ability of the player is as important as the offensive ability, and the limitation of the opponent's score is equivalent to one's attack opportunity. In defensive basketball, mainly defensive awareness and physical quality, all of which need long-term training and training. Whether it's horizontal movement in defense or judging the timing of shooting, it reflects the comprehensive ability of players. In the basketball training of colleges and universities, we should pay attention to the training of players' physical quality, physical strength, ensure the strength and concentration of defense, and let players summarize their defensive experience in actual combat to develop their defensive awareness[4].

Basketball is an art movement, all five players in sports including the use of many tactics, whether offensive or defensive tactics have a lot of cooperation, can improve the overall strength of five strong player to maximize the difference between the teams is also a decisive factor. Good understanding of the tactical need players coach with the central idea of implementing tactics of the coach is the basic quality of great players, whether it is responsible for organizing the guard or other position in the team, they need to develop their own tactics, the most simple and most efficient way to obtain the score, which not only can save energy, can also be make the sport of basketball has become more specialized and ornamental.

In the basketball offensive is applied to a part of most of the tactics of college basketball teaching should focus on the basic tactics of the patient explain complex tactical needs of every small tactical implementation in place, for example, want to make a pitcher shooting opportunities without ball, and requires all the players with tactics and a simple pick and roll cover, anti run or pass plus pitcher, can create an effective attack opportunity. In college basketball tactics teaching, should uphold the long-term learning purpose, the player coach in the long-term implement in actual combat tactics, cultivating the tactical awareness of their own, and use the most reasonable tactical system under different conditions in actual combat, to attack mode then strain. For example, if the other players are big players, we should speed up the offensive tactics rhythm, running open, give us the opportunity to manufacture the pitcher pitching, or give us back to speed advantage on the other side of center of attack; another example to prevent our attack in the founder's line we should be appropriate, "in play", involved in the defense, the other defensive players struggling to run, finally get a mobile phone. The attacking tactics of basketball are varied, but the basic qualities of the players can not be separated from the players, and the clever players can complete the master's offensive performance [5].

In the basketball defense will also use a lot of tactics, such as a full court press, defense or defense area, the coach will refer to the situation in the field of targeted arrangement of defensive tactics, and as players need to connect each defensive tactics of their tasks and do good. For example, in the opening when the coach generally take regional defense strategy, in order to save the team's strength, and defend our inside; if the other players have the ability to highlight or shooting more accurate, our coach usually used in defense, even two people to defend a person defense tactics; in addition, the situation in time the more anxious, the proper use of full court defensive strategy, can also disrupt each other's attitude and way of attack.

The game of basketball is a kind of psychological game and the embodiment of the IQ of basketball. It is particularly important in the teaching of basketball in Colleges and universities, and it is the theoretical basis of playing basketball. While growing college students are paying attention to physical exercise, they also need to learn more about basketball tactical knowledge, and apply 
them to practice, and accumulate experience in practice and constantly improve their ability to use techniques and tactics.

Physical quality is the fundamental condition for the execution of basketball technical and tactical execution. A player who cannot run or jump will eventually be knocked out of the fierce basketball competition. Excellent physical quality is the fundamental guarantee for high intensity competition, which not only reduces players' accidental injuries, but also ensures coaches' tactical execution [6].

The three most important physical qualities in basketball are speed, strength and explosive power. First of all, the speed of reflected in basketball breakthrough and break, such as the great star Allen Iverson, is to have a super speed, speed to get rid of the defender and find opportunities to score in the team; if there is a break to two fast players, will make the whole fast as cloud water move smoothly. In addition, more and more power is used in basketball, basketball tactics and systems are constantly with the cognition, has rarely play perfect basketball match, as it was some one person strong, the strong need strong force to complete, has the superiority in the physical confrontation even complete the "brilliant performance of the two plus one". Strong power control can not only make the players' technical movements more standard, but also improve the durability and defense of the players. In modern basketball, explosive force is also a standard to measure players' quality. A player who jumps higher than others and has more impact is always attracting much attention.

Modern college basketball, especially basketball teaching in our country, not only from the institutional reform, also need players from physical work on, from diet to exercise, to complete training system, the muscle is not a day of practice, the basketball ability need to slowly raise, the only constant of basketball athletes special physical training effectively, by enhancing the running and jumping ability and combat ability, to improve the comprehensive ability of the whole team.

\section{Conclusions}

In recent years, China's colleges and universities are constantly deepening the understanding of the new rules of FIBA, and in college basketball education is also constantly in line with the world. The core of FIBA's new rules is to expand the three point distance, expand the area and increase the attack area of three seconds. Change according to these rules, we know that only in Basketball Teaching in university culture, players comprehensive basketball players to improve understanding of tactics and enhancing the physical quality of players to adapt to the new era in basketball at the same time, fundamentally improve the level of basketball China.

\section{References}

[1] Zhuang-Zhi D, Wang X J. Influence and Countermeasures of New 3-Pointer Rules on Basketball Match [J]. Journal of Henan Institute of Education, 2011.

[2] Li Y, Finance S O. Research on the Influence Factors and Countermeasures of Female Workers' Career Development in the Colleges and Universities of Yunnan Province [J]. Journal of Baoshan University, 2017.

[3] Ning Y, Zhang B, Liu X, et al. Influence and Countermeasures of the Merger of Colleges and Universities of Different Levels on Teaching Administration[J]. Journal of Hebei Normal University of Science \& Technology, 2008.

[4] Ji-Chun L U. On the Influence and Countermeasures of Credit System on the Library Work in Colleges and Universities [J]. Journal of Baoding Teachers College, 2007.

[5] Jiao Y, Chen R, Graduate Department. The Influence of the Revision of FIBA Basketball Rules in 2014 On Basketball Competitions [J]. Journal of Anhui Sports Science, 2015.

[6] Yang J X, Li J. Analysis on factors influencing the quality of Shadow Boxing teaching and countermeasures in colleges and universities[J]. Zhejiang Sport Science, 2004. 